\title{
Computed tomographic colonography with the step-clipping method detects a previously bleeding diverticulum
}

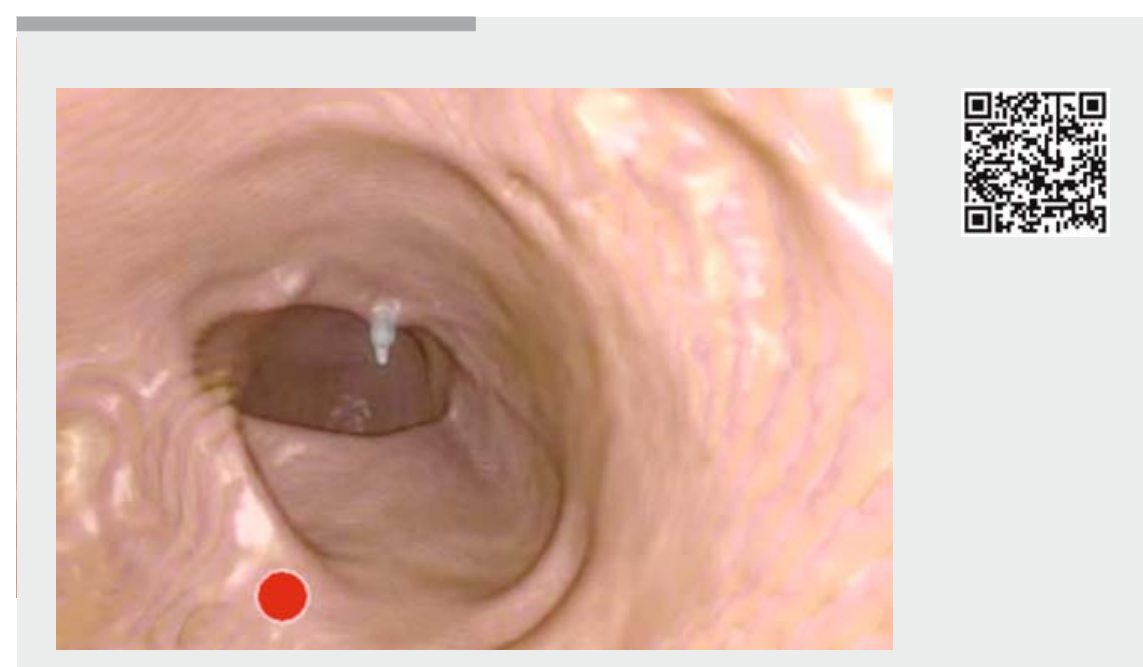

$\checkmark$ Video 1 Seven marking clips placed on the colon serve as artificial indicators. Computed tomographic colonography provides 3-dimensional information about the relationship of the responsible lesion and each clip.

Low completion rate of endoscopic treatment for colon diverticular bleeding remains troublesome because of the difficulty in determining the responsible diverticulum after spontaneous cessation of bleeding. Extravasation, observed on contrast-enhanced computed tomography (CECT), is an important factor in identifying a bleeding diverticulum. However, the detection rate using colonoscopy is not satisfactory, with a $\leq 60 \%$ chance of lesion detection [1,2] because colonoscopy does not provide as much precise positional information as CT. The "step-clipping" method uses endoclips to create artificial indicators in the colon [3], formulating a positional relationship between the responsible diverticulum and each clip. Combination of this technique with computed tomographic colonography (CTC), which is recommended for neoplastic lesions [4], may identify a silent lesion ( $\triangleright$ Video 1 ).

A 58-year-old man was admitted with massive hematochezia. Five previous colonoscopic examinations during four previous consecutive admissions failed to detect the responsible lesion. Extrava- sation was detected from one of the numerous diverticula in the ascending colon on CECT conducted upon admission ( $\triangleright$ Fig.1). However, subsequent colonoscopy found no active bleeding. After a minimal search, we placed seven marking clips, 2 inches apart, from the ascending colon to the transverse colon (> Fig.2, "step-clipping” method), and performed unenhanced CT.

The responsible diverticulum, identified on initial CECT, was determined on the unenhanced $C T$, and then marked digitally ( $\mathbf{F i g} \cdot \mathbf{3 a}$ ). Synchronized CTC was performed, which revealed that the digital mark was placed opposite the 6th clip and beyond a fold in front of it ( $\triangleright$ Fig.3b). Based on this evaluation, colonoscopy successfully identified the responsible diverticulum ( $\mathbf{F i g . 4}$ ), resulting in endoscopic band ligation.

Information regarding the haustra and circumferential assessment are difficult to acquire from conventional CT axial imaging. CTC can overcome these limitations and is an appropriate simulation before colonoscopy. Clip marking on CTC provides 3-dimensional relation-

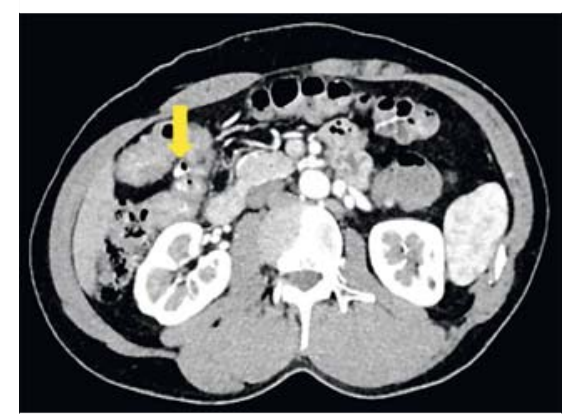

- Fig. 1 Contrast-enhanced computed tomography image taken on admission day showing extravasation from one of the diverticula in the ascending colon (yellow arrow).

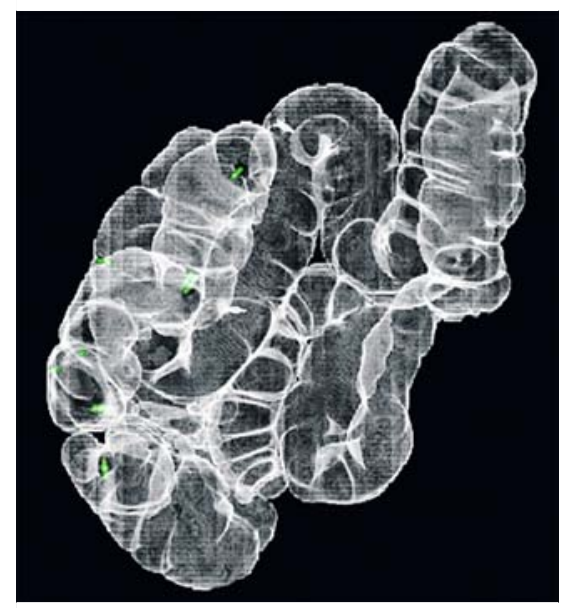

- Fig. 2 Seven clips were placed from the ascending colon to the transverse colon, 2 inches apart. Colonography schematically represents the position of the seven clips.

ships with the responsible diverticulum, thus demonstrating its clinical feasibility.

Endoscopy_UCTN_Code_TTT_1AQ_2AB

Competing interests

None 

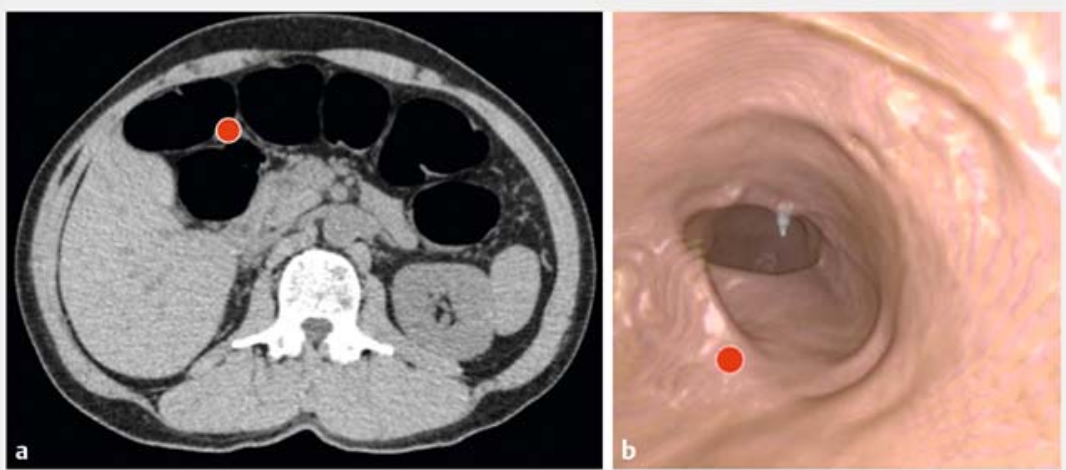

- Fig. 3 Identification of the responsible diverticulum. a Unenhanced computed tomography after "step-clipping." The responsible diverticulum, identified on initial contrast-enhanced computed tomography, was determined and marked digitally (red-colored circle). b Computed tomographic colonography showed a synchronously marked diverticulum opposite the 6th clip and beyond a fold in front of it.

The authors

Hirosato Tamari ${ }^{1}$, Taiki Aoyama ${ }^{1}$, Kenjiro Shigita², Naoki Asayama' ${ }^{1}$, Akira Fukumoto², Shinichi Mukai' ${ }^{1}$, Shinji Nagata ${ }^{1}$

1 Department of Gastroenterology, Hiroshima City Asa Citizens Hospital, Hiroshima, Japan

2 Department of Endoscopy, Hiroshima City Asa Citizens Hospital, Hiroshima, Japan

\section{Corresponding author}

\section{Taiki Aoyama, MD}

Department of Gastroenterology, Hiroshima City Asa Citizens Hospital, 2-1-1 Kabeminami, Asakita-ku, Hiroshima 731-0293, Japan

Fax: +81-82-8141791

t-aoyama@asa-hosp.city.hiroshima.jp

\section{References}

[1] Sugiyama T, Hirata Y, Kojima Y et al. Efficacy of contrast-enhanced computed tomography for the treatment strategy of colonic diverticular bleeding. Intern Med 2015; 54 : $2961-2967$

[2] Obana T, Fujita N, Sugita R et al. Prospective evaluation of contrast-enhanced computed tomography for the detection of colonic diverticular bleeding. Dig Dis Sci 2013; 58: $1985-1990$

[3] Tamari H, Aoyama T, Nagata S et al. "Stepclipping" method: a technique for detecting previously bleeding diverticula. Endoscopy 2018; 50: E10-E12

[4] Spada C, Stoker J, Alarcon O et al. Clinical indications for computed tomographic colonography: European Society of Gastrointestinal Endoscopy (ESGE) and European Society of Gastrointestinal and Abdominal Radiology (ESGAR) Guideline. Endoscopy 2014; 46: 897-915

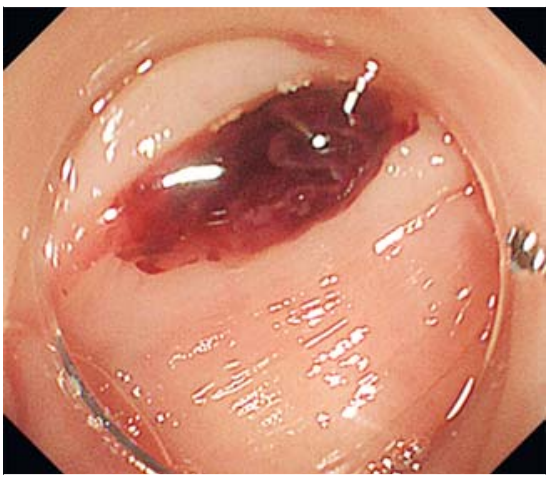

- Fig. 4 Colonoscopy successfully identified the responsible diverticulum with a clot on the orifice of the diverticulum.

\section{Bibliography}

DOI https://doi.org/10.1055/a-0805-0963

Published online: 11.12.2018

Endoscopy 2019; 51: E32-E33

(c) Georg Thieme Verlag KG

Stuttgart · New York

ISSN 0013-726X

\section{ENDOSCOPY E-VIDEOS}

https://eref.thieme.de/e-videos

口回 Endoscopy E-Videos is a free ys access online section, reporting 田: on interesting cases and new techniques in gastroenterological endoscopy. All papers include a high quality video and all contributions are freely accessible online.

This section has its own submission website at https://mc.manuscriptcentral.com/e-videos 